\title{
Alterações no contexto escolar: rumo ao desenvolvimento de um Web Currículo
}

\author{
Marlusa Benedetti da Rosa ${ }^{1,2,3}$ (marlusa.benedetti@ufrgs.br) \\ Léa da Cruz Fagundes ${ }^{1,2}$ (leafagun@ufrgs.br) \\ Marcus Vinicius de Azevedo Basso ${ }^{1,4,5}$ (mbasso@ufrgs.br) \\ ${ }^{1}$ Laboratório de Estudos Cognitivos (LEC/UFRGS) \\ ${ }^{2}$ Programa de Pós-Graduação em Informática na Educação(PPGIE/UFRGS) \\ ${ }^{3}$ Colégio de Aplicação - Universidade Federal do Rio Grande do Sul (Cap/UFRGS) \\ ${ }^{4}$ Instituto de Matemática - Universidade Federal do Rio Grande do Sul (IM/UFRGS) \\ ${ }^{5}$ Programa de Pós-Graduação em Ensino de Matemática (PPGEMAT/UFRGS)
}

\begin{abstract}
Resumo: $O$ presente trabalho é parte da pesquisa de doutorado na área da informática na educação que propõe mediante um estudo experimental gerar indicadores para a constituição de um modelo curricular que integra a tecnologia digital na educação básica denominando-o de Web Currículo. O estudo se realiza no Colégio de Aplicação da UFRGS num contexto que contempla o desenvolvimento de projetos aprendizagem na modalidade de iniciação científica e a utilização de laptops educacionais do Projeto UCA. Neste artigo, apresenta-se a análise das possibilidades de mudança no contexto escolar a partir dos materiais, crenças e condutas dos sujeitos da pesquisa. Utilizando como fundamentação teórica a epistemologia genética e como metodologia a observação participante e a análise textual discursiva.
\end{abstract}

Palavras-Chaves: Web currículo, inclusão digital, iniciação científica, laptop educacional

\section{Changes in the school contexto: towards development of a Web Curriculum}

\begin{abstract}
This work is part of doctoral research in area of information technology in educationby proposing an experimental study to generate indicators for the establishment of acurriculum model that integrates digital technology in basic education calling it Web Curriculum. The study is being performed in the Colégio de Aplicação da UFRGS in a context that includes the development of learning projects in the form of undergraduate research and educational use of laptops at UCA Project. This article presents the analysis of the possibilities of change in the school context from the materials, beliefs and behavior of research subjects. Using as the theoretical genetic epistemology and methodology as participant observation and textual analysis of discourse.
\end{abstract}

Keywords: curriculum web, digital inclusion, educational laptop, scientific initiation

\section{Introdução}

A imersão da escola na cultura digital oportunizada pela chegada dos laptops educacionais referentes ao Projeto Um Computador por Aluno ${ }^{1}$ se constitui como um espaço experimental para o desenvolvimento de modelos pedagógicos diferenciados. A portabilidade do equipamento permite um uso diferenciado em sala de aula e amplia a realização de atividades pedagógicas capazes de integrar a tecnologia digital ao currículo. 
O acesso à tecnologia digital na modalidade "um computador por aluno" (ou "um para um"), redimensiona o tempo e o espaço da sala de aula. Enquanto no modelo de laboratório (um para muitos) o uso dos equipamentos é feito em regime compartilhado, exigindo agendamento e planejamento prévio de atividades, o modelo um para um, permite a utilização concomitante por todos os alunos na escola. Além disso, a portabilidade dos equipamentos permite a utilização em atividades que transcendem o contexto escolar.

Se antes os alunos precisavam se deslocar para o laboratório de informática, hoje, com a chegada dos laptops conectados à rede, são ultrapassadas as paredes da escola. Os alunos estão conectados ao mundo e precisam explorar esse mundo, contribuindo para sua melhoria. Essa mudança de paradigma nos permite acreditar que o Projeto UCA se constitua como uma oportunidade real de rompimento com metodologias centradas na transmissão e fragmentação do conhecimento.

Hoffman e Fagundes (2008) afirmam que incluir a escola na cultura digital é mais do que simplesmente possibilitar o acesso às tecnologias da informação e apresentam os laptops como uma possibilidade de imersão da escola nessa cultura. Para tanto, é necessário criar condições para que a internet e a rede de computadores façam parte da realidade dos indivíduos e da instituição beneficiada. Ou seja, "incluir é envolver, inserir e relacionar; é fazer parte, é causa efeito; é possibilitar o acesso à informação bem como a produção de informação."(Hoffman e Fagundes ,2008, p.4)

Acredita-se que a mudança na cultura escolar vislumbrada pela sociedade do conhecimento só será eficaz quando expressar inovações e transformações dentro do próprio ambiente escolar. Neste artigo, as crenças, as condutas e os materiais utilizados durante o desenvolvimento dos projetos de aprendizagem na modalidade de iniciação científica, associados ao uso dos laptops educacionais, serão analisados com o objetivo de visualizar possibilidades de mudanças no contexto escolar. Nas seções seguintes apresenta-se a utilização dos laptops relacionando seu uso com as possibilidades de mudança no currículo durante o planejamento e desenvolvimento dos projetos de aprendizagem na modalidade de iniciação científica. Na sequência, justifica-se a escolha do Projeto Pixel como espaço destinado a coleta de dados a partir da sua contextualização dentro da estrutura curricular do Colégio de Aplicação da Universidade Federal do Rio Grande do Sul- CAp-UFRGS. Descreve-se como foi feita a coleta de dados e as etapas da análise textual discursiva utilizadas para este estudo e, finalmente, são feitas considerações sobre as contribuições do mesmo em relação às perspectivas de desenvolvimento da tese.

\section{Laptop na sala de aula: rumo à construção do Web Currículo}

Os estudos de Fullan $(2008,2009)$ sobre a mudança educacional indicam que a constituição de comunidades de aprendizagem tem relação com a efetivação das mudanças no contexto escolar. Nas palavras do autor, "As ansiedades da incerteza e as alegrias do domínio são centrais para o significado subjetivo da mudança educacional e para o seu sucesso ou fracasso.” (Fullan, 2009, p. 32)

Considerando que a inovação escolar é multidimensional e que qualquer novo programa ou política necessita contemplar espaços capazes de gerar significados diferentes, Fullan $(2008,2009)$ aponta como três as condições básicas para a mudança: o uso que se faz dos materiais, os comportamentos dos sujeitos envolvidos no processo e crenças dos professores. Neste artigo, substituiremos o termo comportamentos por condutas, a fim de evitar equívocos em relação à sobrecarga empirista que o termo comportamento traz do senso comum.

V. $10 \mathrm{~N}^{\mathrm{o}} 1$, julho, 2012 
O autor ressalta que a mudança nas condutas ou no estilo de usar os materiais curriculares representa uma dificuldade maior, quando devem ser adquiridas novas habilidades e desenvolvidas novas maneiras de realizar as atividades de ensino. As mudanças nas crenças dos profissionais da educação são ainda mais difíceis. Elas desafiam os valores básicos dos indivíduos em relação aos propósitos da educação. Além disso, as crenças muitas vezes não são explícitas, discutidas ou entendidas, mas são embutidas no nível de pressupostos não declarados. Logo, para que ocorra uma verdadeira mudança, o desenvolvimento de novos entendimentos por parte dos professores é essencial. As crenças dos professores proporcionam um conjunto de critérios para o planejamento geral e um filtro para separar oportunidades valiosas de aprendizagem e de oportunidades não tão valiosas. (Fullan, 2009 p. 44)

Os argumentos de Fullan (2009) colaboram com os estudos de Hoffman e Fagundes (2008) em relação ao desenvolvimento de projetos de aprendizagem e as mudanças no contexto de uma das escolas participantes do Piloto UCA. Neste artigo, pretende-se visualizar a mudança na escola provocada pela chegada dos laptops, inicialmente como uma experiência pessoal de cada professor, podendo esta originar novos domínios sobre a tecnologia, chegando a realização e crescimento profissional. Isso por que “(...) para construir conhecimento, é preciso reestruturar as significações anteriores, produzindo boas diferenciações e integrando ao sistema as novas significações." (Fagundes, et al., 1999, p.24)

Considerando que em qualquer situação de aprendizagem os movimentos de assimilação e acomodação são responsáveis pela constituição de novas estruturas, o processo geral de equilibração, responsável pela aquisição do conhecimento humano, justifica as dificuldades de mudança no contexto escolar provocadas pela inserção das tecnologias digitais, no caso os laptops. (Piaget, 1975)

A compreensão de uma nova proposta curricular depende dos sistemas lógicos dos professores em relação às produções dos alunos. Ao interagir com os alunos e com os laptops, os professores assimilam as situações de intervenção que permitiram o desenvolvimento cognitivo dos alunos e, estes, acabam sendo incorporados a novos sistemas lógicos que auxiliaram os professores a resolver novas estratégias de intervenção. Ou seja, a mudança no contexto escolar provocada pelo uso dos laptops é produto de uma atividade intencional, da interatividade cognitiva entre a equipe de professores e alunos, considerando, portanto "as trocas afetivas, investimento de interesses e valores..." (Fagundes, et al., 1999, p.24)

O problema central da mudança curricular está na dificuldade que as propostas e programas curriculares têm de levar em consideração as realidades subjetivas e os contextos individuais e organizacionais das instituições. Levar em consideração as realidades é fundamental para que as mudanças potenciais se tornem significativas no contexto da sala de aula. Tendo em vista que, as crenças, condutas e os materiais utilizados fazem referência às teorias pedagógicas subjacentes ao projeto em desenvolvimento, é preciso considerar que:

"Um professor pode usar novos materiais ou tecnologias curriculares sem alterar a abordagem de ensino, ou pode usar os materiais para alterar alguns comportamentos relacionados com o ensino, mas sem entender as concepções e crenças subjacentes à mudança." (Fullan, 2009, p. 39)

Neste trabalho, assume-se que os projetos de iniciação científica associados ao uso dos laptops educacionais na modalidade um para um, tem oportunidade de gerar, a partir dos debates coletivos, tomadas de consciência sobre o significado que o currículo assume no contexto da inclusão digital. 
Acredita-se que a inclusão digital emerge quando, dentro das escolas, há espaços para a reflexão coletiva sobre o projeto político-pedagógico. Isto porque, cada professor precisa se sentir desafiado a pensar a sua área do conhecimento inserida no currículo de modo interdependente, ou seja, em sua dimensão irredutível, complementar e indissociável do conhecimento de cada sujeito. Neste sentido, o modelo de Web Currículo parece ser o mais apropriado para oportunizar uma verdadeira inclusão digital.

O termo "Web" representa a possibilidade de produzir e compartilhar o conhecimento no mundo complexo em que vivemos, enquanto que o termo "currículo" representa todas as relações que os sujeitos estabelecem com esse conhecimento. Assim, o Web Currículo propõe-se a considerar como o conhecimento se relaciona com o contexto no qual é produzido e qual o seu papel na sociedade como um todo. Essa é uma da facetas da inclusão digital "possibilitar o acesso à informação bem como a produção de informação"(Hoffman e Fagundes , 2008)

Almeida e Silva (2011) propõem o Web Currículo como um currículo que se desenvolve por meio das tecnologias digitais de informação e comunicação. O Web Currículo é capaz de incorporar as características do meio digital no currículo considerando o processo experienciado durante o seu desenvolvimento.

São fontes geradoras do Web Currículo: a interação, o trabalho colaborativo e o protagonismo de todos atores envolvidos no processo. Para que o Web Currículo germine, o projeto pedagógico necessita estar fundamentado na intencionalidade de propiciar, a partir dos conhecimentos construídos na ação, o aprendizado dos conhecimentos científicos. (Assis, et Al., 2010)

No contexto deste estudo, o Web Currículo se constitui como uma rede de conceitos que se estabelece a partir de estruturas de significação evidenciadas pelos sujeitos participantes do processo de aprendizagem no qual estão imersos. Ele emergirá dos avanços conceituais evidenciados na relação que se estabelece entre o conhecimento e o contexto no qual é produzido. As características do meio digital serão incorporadas ao currículo a partir dos possíveis engendrados (Piaget, 1985) pelos professores em conjunto com seus alunos durante o desenvolvimento dos projetos de aprendizagem na modalidade de iniciação científica.

Entende-se que, durante o desenvolvimento dos projetos de aprendizagem na modalidade iniciação científica, o Web Currículo se constituirá como uma rede que se estabelece a partir dos conceitos estudados e evidenciados pelos sujeitos participantes do processo. Estima-se que os professores e alunos envolvidos na investigação possam estabelecer conexões entre o cotidiano, as atitudes e os procedimentos utilizados durante o processo de conceituação.

Considera-se que, a partir da curiosidade dos alunos, será possível, ao professor, conhecer o sistema de significações de que seu aluno dispõe naquele momento. No entanto, para ampliar esse sistema, será preciso superar seus limites, ou seja, com base nas dúvidas dos alunos, caberá ao professor problematizar o sistema, criar situações nas quais os alunos possam relacioná-lo com outras situações em que estejam presentes diversos valores, conceitos e contextos.

Os laptops com conexão a rede também terão um papel importante nesse processo de acompanhamento do trabalho dos alunos. Ao registrar seus trabalhos em Wikis, os alunos, fornecerão aos professores possibilidades de acompanhar os estudos e as escolhas que o levaram a elaborar determinadas conclusões. É importante considerar a possibilidade de inserção de links, imagens, vídeos, sons, os quais podem ser visualizados tanto pelos professores quanto pelos colegas.

V. $10 \mathrm{~N}^{\mathrm{o}} 1$, julho, 2012 
Em cada projeto de aprendizagem na modalidade de iniciação científica, surgem códigos e símbolos relacionados ao tema que está sendo pesquisado. Neste momento, cabe aos professores ficarem atentos às questões dos alunos orientando-os na busca de novos caminhos que o levem a superação das dificuldades através da problematização dos aspectos negligenciados por eles.

\section{Contextualização do estudo}

O CAp-UFRGS trás na sua essência a busca pela geração de propostas pedagógicas inovadoras. $\mathrm{O}$ trabalho com projetos de aprendizagem teve como marco principal o surgimento do Projeto Amora em 1996. Ocorre que, a partir da necessidade de implementar o ensino fundamental de nove anos e da previsão de recebimento dos laptops do Projeto UCA, a instituição retomou as discussões sobre o currículo e o projeto político pedagógico da escola.

Como dinâmica para refletir e propor alterações curriculares, a coordenação pedagógica da escola Comissão de Ensino $\mathrm{COMEN}^{2}$, organizou espaços de reunião envolvendo todos os docentes. Ao longo de 2008 e 2009, os professores do CApUFRGS participaram de reuniões pedagógicas que aconteciam nas quartas-feiras à tarde. Os docentes participaram de dois grupos: um envolvendo somente os professores especialistas de cada uma das diferentes áreas do conhecimento - reuniões de área e outro envolvendo pelo menos um representante de cada área do conhecimento reuniões de equipes de trabalho.

As equipes foram constituídas por professores de todas as áreas do conhecimento que atendiam alunos com faixas etárias semelhantes, assim denominadas: (a) Equipe Séries iniciais: $1^{\circ}$ ao $5^{\circ}$ ano do Ensino Fundamental; (b) Equipe Amora: $6^{\circ}$ e e $7^{\circ}$ anos do Ensino Fundamental; (c) Equipe Pixel: $8^{\circ}$ e $9^{\circ}$ anos do Fundamental; (d) Equipe Ensino Médio Inovador: $1^{\circ}, 2^{\circ}$ e $3^{\circ}$ anos do Ensino Médio; (e) Equipe EJA: Educação de jovens e adultos no Ensino Fundamental e Médio. ${ }^{3}$

As mudanças propostas contemplaram o que os professores de cada equipe consideraram necessário. Todas as equipes organizaram meios para desenvolver o trabalho com projetos de iniciação científica. Neste contexto, surgem os projetos de aprendizagem na modalidade de iniciação científica os quais tem os mesmos objetivos dos projetos de aprendizagem propostos por (Fagundes, et al., 1999), porém desde o início procuram inserir a terminologia da iniciação cientifica: perguntas iniciais e secundárias, justificativa, metodologia, referências. Os mesmos podem ser considerados o elo que permite o estabelecimento da ligação entre as diferentes áreas do conhecimento e as diferentes séries que compõem o currículo do CAp-UFRGS.

Atualmente, no currículo de todos os alunos do CAp-UFRGS, há horários destinados aos projetos de iniciação científica. Nestes horários os alunos contam com a presença de professores especialistas de todas as áreas do conhecimento. A garantia de vários especialistas nos horários destinados aos projetos iniciação científica tem o objetivo oportunizar momentos de orientação interdisciplinar e de garantir um número pequeno de orientandos por professor.

No ano de 2010, além das mudanças curriculares implementadas, o CApUFRGS recebeu os laptops educacionais da primeira fase do Projeto UCA. As combinações quanto à distribuição e o uso dos laptops foram feitas dentro das equipes de trabalho, assim como, o planejamento e as estratégias de avaliação também são desenvolvidos a partir das decisões tomadas em conjunto pelos professores.

\section{Coleta e análise dos dados:}


Neste estudo, serão apresentados dados coletados no Projeto Pixel. Ele é formado pelos alunos e professores que atuam na sétima e oitava séries (oitavo e nono anos a partir de 2013) do CAp-UFRGS. Nos momentos destinados ao desenvolvimento dos projetos de iniciação científica, o grupo de alunos fica dividido em oito grupos de pesquisa com aproximadamente quinze alunos. Cada grupo conta com um professor orientador de língua estrangeira podendo ser: língua inglesa, língua alemã, língua espanhola ou língua francesa. Além dos professores de língua estrangeira, durante os períodos destinados ao desenvolvimento dos projetos de iniciação científica, os alunos contam com a presença de professores de outras áreas.

A decisão de acompanhar o Projeto Pixel deveu-se a vários motivos: (a) tratase de um grupo de professores que apresentou dificuldades para se organizar na condição de equipe no início do trabalho; (b) a equipe atende alunos oriundos do Projeto Amora, (c) na sétima série há ingresso de alunos provenientes de outras escolas, assim, em cada turma do Projeto Pixel, temos alunos que já trabalharam com iniciação científica e outros que estão iniciando o processo. (d) os alunos que participam do Projeto Pixel, segundo a Epistemologia Genética, pertencem a uma faixa etária importante no que se refere à construção lógica e à abertura dos possíveis. (e) o currículo está organizado em dois tipos de espaços: um destinado aos projetos de iniciação científica e outro destinado às áreas específicas (Língua Portuguesa, Língua Espanhola, Língua Alemã, Língua Inglesa, Língua Francesa, Matemática, Ciências, Artes Visuais, Música, Teatro, Geografia, História e Educação Física).

Os dados apresentados, neste estudo, são de natureza qualitativa e foram coletados através de observação participante (Bogdan e Bicklen,1994). A coleta de dados se deu por meio do acompanhamento do grupo de professores e alunos do CApUFRGS participantes do Projeto Pixel. A observação participante aconteceu em dois momentos: (a) acompanhamento de dois grupos de alunos pertencentes à sétima e à oitava série do ensino fundamental durante os quatro períodos semanais destinados à orientação e ao desenvolvimento dos projetos de iniciação científica e (b) acompanhamento das reuniões pedagógicas dos professores, cujo objetivo é o planejamento e a articulação das atividades de iniciação científica que são desenvolvidas em conjunto com os alunos.

A fim de identificar as possibilidades de mudança de significado no contexto escolar que se estabeleceu, foram produzidos vídeos os quais estão em fase de transcrição. Para este artigo, com o auxílio do Software Nvivo ${ }^{4}$, foram feitas transcrições de quatro vídeos relativos as reuniões de planejamento dos professores referentes aos meses de maio e junho de 2011. Acompanhou-se, durante o segundo semestre de 2011, um grupo de sétima série e um grupo de oitava série nos dois encontros semanais de uma hora e meia cada destinados ao desenvolvimento dos projetos de iniciação científica.

Os textos obtidos a partir da transcrição das reuniões de planejamento foram submetidos ao processo de análise textual discursiva:

A análise textual discursiva é descrita como um processo que se inicia com uma unitarização em que os textos são separados em unidades de significado. Estas unidades por si mesmas podem gerar outros conjuntos de unidades oriundas da interlocução empírica, da interlocução teórica e das interpretações feitas pelo pesquisador. (Moraes e Galiazzi, 2006, p. 118)

Os textos relativos às transcrições passaram por várias etapas. Inicialmente, foi feita a leitura das transcrições eliminando falas que não tivessem relação com o tema abordado (questões específicas de alunos, combinações administrativas como datas e 
avisos). A segunda etapa consistiu na leitura das transcrições, com o objetivo de se constituir as unidades de análise. Logo após as unidades foram classificadas em uma das categorias iniciais: as crenças, condutas e os materiais.

$\mathrm{Na}$ categoria materiais foram registradas falas referentes à utilização de materiais, sejam: textos, vídeos, laptops, livros, entre outros. $\mathrm{Na}$ categoria crenças foram agrupadas falas dos professores em relação as suas expectativas com o Projeto Pixel, e na categoria condutas foram agrupadas as falas dos professores referentes às ações desenvolvidas pelos sujeitos da pesquisa.

Na sequência cada uma das categorias sofreu uma segunda classificação. Devido ao nosso interesse, separaram-se todas as falas referentes a computadores, internet, wikis, blogs, MSN formando a categoria laptops educacionais. Durante a leitura das unidades de significação identificou-se uma diferenciação entre o uso dos materiais produzidos e utilizados, ora pelos professores e ora pelos alunos. Assim, surgiram as categorias intermediárias: materiais dos alunos e materiais dos professores. Da mesma forma, foram organizadas as categorias crenças e condutas, gerando as categorias intermediárias: crenças dos alunos, crenças dos professores, condutas dos alunos e condutas dos professores, respectivamente. Na sequência foi organizado o Tabela A que registra a quantidade de unidades de significado relativas a cada categoria.

Tabela A: Registro da quantidade de unidades de análise em relação as categorias

\begin{tabular}{|l|l|l|l|}
\hline Categorias Iniciais & $\begin{array}{c}\text { Unidades } \\
\text { De Análise }\end{array}$ & \multicolumn{1}{|c|}{ Categorias Intermediárias } & \multicolumn{1}{|c|}{$\begin{array}{c}\text { Unidades } \\
\text { De }\end{array}$} \\
\hline \multirow{2}{*}{ MATERIAIS } & \multirow{2}{*}{54} & Laptos & 9 \\
\cline { 3 - 4 } & & Materiais dos alunos & 13 \\
\cline { 3 - 4 } & & Materiais do professor & 11 \\
\hline \multirow{2}{*}{ CRENÇAS } & \multirow{2}{*}{ CONDUTAS } & Crenças sobre os papéis dos professores & 91 \\
\cline { 3 - 4 } & \multirow{2}{*}{73} & Crenças sobre os papéis dos alunos & 34 \\
\cline { 3 - 4 } & & Condutas dos alunos & 32 \\
\cline { 3 - 4 } & & Condutas dos professores & 41 \\
\hline
\end{tabular}

Uma análise preliminar do Tabela $\mathbf{A}$, indica na fala dos professores uma quantidade muito maior de unidades de significado relativas às suas crenças. A quantidade de unidades de significação relativas aos laptops educacionais é muito inferior. Um olhar mais detalhado sob as subcategorias indica que as crenças dos professores estão muito mais voltadas para a sua atuação enquanto professores do que em relação aos alunos. Fato que poderia nos preocupar, se também existisse indícios de uma pedagogia centrada no professor. No entanto, as categorias intermediárias relativas a conduta indicam a existência de proporção entre o número de unidades de significado relativas a condutas dos alunos e a condutas dos professores.

Durante o processo de categorização ficou evidente que o grupo está vivendo um processo de reflexão coletiva. Para ilustrar nossa inferência, são apresentadas algumas falas dos professores já constituídas como unidades de análise, extraídas da subcategoria Crenças dos professores:

Fala A: "Tem muitas coisas diferentes que a gente faz e cada um tem o seu jeito de fazer e faz, mas, por exemplo, até onde é que vai a nossa intervenção como forma de dar fundamento as questões e a explicação?"

Fala B: "Então é muito difícil porque a gente conta com a ideia, a concepção de cada professor do que é a iniciação científica. Ou seja, a falta de preparo, a falta de conhecimento sobre como fazer isso (iniciação científica) na Educação Básica

Fala C: "Mas isso é diferente da gente ver essa pergunta... É muito ampla. Vamos diminuir? E aí fazer uma intervenção para que ele também perceba isso e que não fique muito artificial."

V. $10 \mathrm{~N}^{\mathrm{o}} 1$, julho, 2012 
Fala D: "E agora se romper esse processo, tá agora nós vamos partir para outra, nós vamos estar tolhendo o processo.

Fala E: "Como propor, metodologias, estratégias pensadas que nós vamos fazer de forma conjunta, para fazer esse processo de transição."

Considerando que apenas mudanças em relação às crenças não significam alterações no contexto escolar buscou-se acompanhar, durante os projetos de iniciação científica, as perspectivas de mudança de conduta no contexto da sala de aula. Os dados resultantes desta análise estão descritos na Tabela B. Eles foram organizados a partir da caracterização dos encontros destinados a realização dos encontros do Projeto Pixel, no segundo semestre de 2011.

A montagem do quadro foi realizada no intuito de caracterizar as etapas da iniciação científica propostas pelo Projeto Pixel e estão descritas na primeira coluna. Na segunda e terceira colunas são apresentadas, respectivamente, as ações dos professores e alunos. Na ultima coluna apresenta-se o número de encontros destinados a cada etapa e a presença ou ausência dos laptops educacionais durante as atividades. Os dados apresentados foram organizados a partir dos registros feitos pela pesquisadora, enquanto acompanhava o desenvolvimento das propostas e a partir dos vídeos produzidos nestes momentos.

Tabela B: Registro das atividades desenvolvidas nos encontros do Pixel.

\begin{tabular}{|c|c|c|c|}
\hline $\begin{array}{l}\text { Etapas da } \\
\text { Iniciação } \\
\text { científica }\end{array}$ & Professores & Alunos & $\begin{array}{l}\mathbf{N}^{0} \text { de encontros/ } \\
\text { Presença dos } \\
\text { laptops }\end{array}$ \\
\hline $\begin{array}{l}\text { Oficinas } \\
\text { desencadeadoras } \\
\text { propostas pelos } \\
\text { professores. }\end{array}$ & $\begin{array}{l}\text { Planejam oficinas, em } \\
\text { conjunto com os alunos, } \\
\text { contemplando as diferentes } \\
\text { áreas do conhecimento com } \\
\text { o objetivo de despertar a } \\
\text { curiosidade. }\end{array}$ & $\begin{array}{l}\text { Planejam as oficinas em } \\
\text { conjunto com os professores e } \\
\text { participam das mesmas } \\
\text { interagindo com os colegas e os } \\
\text { materiais. }\end{array}$ & $\begin{array}{l}\text { Quatro } \\
\text { Ausência }\end{array}$ \\
\hline $\begin{array}{lr}\text { Encontro } & \text { de } \\
\text { discussão } & \text { e } \\
\text { análise } & \text { das } \\
\text { oficinas } & \end{array}$ & $\begin{array}{l}\text { Provocam debates sobre as } \\
\text { experiências vividas durante } \\
\text { as oficinas instigando } \\
\text { ligações entre as } \\
\text { expectativas dos alunos e os } \\
\text { resultados obtidos. }\end{array}$ & $\begin{array}{l}\text { Manifestam suas opiniões sobre } \\
\text { o trabalho desenvolvido, } \\
\text { argumentando a partir das suas } \\
\text { experiências o que conseguiram } \\
\text { elaborar após terem participado } \\
\text { das oficinas. }\end{array}$ & $\begin{array}{l}\text { Um } \\
\text { Ausência }\end{array}$ \\
\hline $\begin{array}{lr}\text { Espaço } & \text { para } \\
\text { elaboração } & \mathrm{e} \\
\text { registro } & \text { das } \\
\text { questões iniciais. }\end{array}$ & $\begin{array}{l}\text { Solicitam aos alunos que } \\
\text { escrevam perguntas do seu } \\
\text { interesse e justifiquem a } \\
\text { escolha das mesmas. }\end{array}$ & $\begin{array}{l}\text { Escrevem uma ou mais questões } \\
\text { e justificam o seu interesse } \\
\text { apresentando os conhecimentos } \\
\text { que já possuem sobre o assunto } \\
\text { escolhido. }\end{array}$ & $\begin{array}{l}\text { Um } \\
\text { Ausência }\end{array}$ \\
\hline $\begin{array}{l}\text { Criação de Wikis } \\
\text { para registro das } \\
\text { produções. }\end{array}$ & $\begin{array}{l}\text { Propõem a criação de } \\
\text { Pbworks para o registro das } \\
\text { questões e justificativas } \\
\text { elaboradas pelos alunos. }\end{array}$ & $\begin{array}{l}\text { Criam suas contas no Pbworks e } \\
\text { e registram as questões e a } \\
\text { justificativa do tema escolhido } \\
\text { nas Wikis }\end{array}$ & $\begin{array}{l}\text { Dois } \\
\text { Presença }\end{array}$ \\
\hline $\begin{array}{lr}\text { Rodadas } & \text { de } \\
\text { apresentação } & \text { das } \\
\text { perguntas } & \text { e } \\
\text { justificativas. } & \end{array}$ & $\begin{array}{l}\text { Propõem a apresentação oral } \\
\text { das questões para o grupo de } \\
\text { alunos com o objetivo de } \\
\begin{array}{l}\text { aproximar pesquisas } \\
\text { semelhantes. }\end{array} \\
\begin{array}{l}\text { Incentivam os alunos a } \\
\text { participarem da apresentação }\end{array}\end{array}$ & $\begin{array}{l}\text { Apresentam oralmente suas } \\
\text { questões e as justificativas sobre } \\
\text { a escolha do tema. } \\
\text { Interagem como os colegas } \\
\text { esclarecendo suas dúvidas sobre } \\
\text { o que foi apresentado e/ou }\end{array}$ & $\begin{array}{l}\text { Dois } \\
\text { Presença }\end{array}$ \\
\hline
\end{tabular}

V. $10 \mathrm{~N}^{\mathrm{o}} 1$, julho, 2012 


\begin{tabular}{|c|c|c|c|}
\hline & dos colegas. & fazendo sugestões dos colegas. & \\
\hline $\begin{array}{l}\text { Momentos } \\
\text { destinados a } \\
\text { busca por } \\
\text { informações } \\
\text { relacionadas ao } \\
\text { tema e ao registro } \\
\text { das mesmas. }\end{array}$ & $\begin{array}{l}\text { Oferecem momentos } \\
\text { destinados para a realização } \\
\text { de pesquisas e registro das } \\
\text { informações na Pbworks }\end{array}$ & $\begin{array}{l}\text { Organizam as informações } \\
\text { solicitadas pelo professor na } \\
\text { Pbworks, registrando: } \\
\text { a) contexto no qual está } \\
\text { caracterizada a pesquisa; b) as } \\
\text { questões que lhe são } \\
\text { significativas sobre aquele tema } \\
\text { naquele contexto; c) as metas, } \\
\text { ações e resultados para } \\
\text { responder questões iniciais. }\end{array}$ & $\begin{array}{l}\text { Vinte } \\
\text { Presença }\end{array}$ \\
\hline $\begin{array}{l}\text { Etapas da } \\
\text { Iniciação } \\
\text { científica }\end{array}$ & Professores & Alunos & $\begin{array}{l}\mathrm{N}^{0} \text { de encontros/ } \\
\text { Presença dos } \\
\text { laptops }\end{array}$ \\
\hline $\begin{array}{lr}\text { Rodada } & \text { de } \\
\text { apresentação das } \\
\text { produções } & \mathrm{e} \\
\text { estratégias } & \\
\text { metodológicas } & \\
\text { escolhidas } & \end{array}$ & $\begin{array}{l}\text { Propõem, aos alunos, a } \\
\text { apresentação da pesquisa em } \\
\text { andamento com o objetivo } \\
\text { de visualizar a articulação } \\
\text { entre o tema e o processo de } \\
\text { desenvolvimento da mesma. } \\
\text { Incentivam os alunos a } \\
\text { participarem da apresentação } \\
\text { dos colegas. }\end{array}$ & $\begin{array}{l}\text { Apresentam os registros feitos } \\
\text { nas Wikis explicando as fontes e } \\
\text { metodologia utilizada na } \\
\text { pesquisa. Comentam os } \\
\text { resultados obtidos e as } \\
\text { perspectivas para continuidade } \\
\text { do trabalho. } \\
\text { Interagem como os colegas } \\
\text { esclarecendo suas dúvidas sobre } \\
\text { o que foi apresentado e/ou } \\
\text { fazendo sugestões dos colegas. }\end{array}$ & $\begin{array}{l}\text { Três } \\
\text { Presença }\end{array}$ \\
\hline $\begin{array}{l}\text { Preparação das } \\
\text { apresentações } \\
\text { para a Mostra de } \\
\text { Iniciação } \\
\text { científica }\end{array}$ & $\begin{array}{l}\text { Propõe a organização de } \\
\text { apresentações que } \\
\text { expliquem o processo de } \\
\text { pesquisa e relacionem com } \\
\text { situações da realidade, as } \\
\text { quais, serão apresentadas } \\
\text { para a comunidade escolar. }\end{array}$ & $\begin{array}{l}\text { Desenvolve estratégias de } \\
\text { apresentação do seu trabalho } \\
\text { que extrapolem o contexto do } \\
\text { grupo de pesquisa do qual } \\
\text { participou, criando dinâmicas } \\
\text { superam o registro escrito com o } \\
\text { objetivo de apresentar o } \\
\text { processo e os resultados obtidos } \\
\text { na pesquisa. }\end{array}$ & $\begin{array}{l}\text { Três } \\
\text { Presença }\end{array}$ \\
\hline $\begin{array}{lr}\text { Apresentação dos } \\
\text { trabalhos } & \text { nas } \\
\text { Mostras } & \text { de } \\
\text { Iniciação } & \\
\text { científica } & \end{array}$ & $\begin{array}{lcr}\text { Organizam } & \text { os } & \text { espaços } \text { e } \\
\text { auxiliam } & \text { os } & \text { alunos } \\
\text { preparando } & \text { os } & \text { recursos } \\
\text { necessários } & & \text { para } \\
\text { apresentação: } & & \text { projetores, } \\
\text { televisores, } & \text { salas } \\
\text { diferenciadas... } & \end{array}$ & $\begin{array}{l}\text { Apresentam os resultados das } \\
\text { suas pesquisas à comunidade } \\
\text { escolar utilizando: encenações, } \\
\text { panfletos, workshops, vídeos, } \\
\text { palestras.... }\end{array}$ & $\begin{array}{l}\text { Dois } \\
\text { Presença }\end{array}$ \\
\hline
\end{tabular}

Ao todo foram acompanhados 37 encontros destinados à realização de projetos de iniciação científica, destes, 27 foram desenvolvidos com a utilização dos laptops educacionais. Do total de encontros, seis foram destinados à realização de oficinas e debates sobre as mesmas, cinco ao refinamento do projeto e a constituição de grupos de trabalho e seis a apresentações coletivas das produções visando o aperfeiçoamento das mesmas. Ou seja, aproximadamente $42 \%$ dos encontros envolveram a participação coletiva dos alunos e os outros $58 \%$ destinaram-se momentos individuais de pesquisa, orientação e registros das informações obtidas. 
A Tabela B evidência que durante as diferentes etapas da iniciação científica os professores criaram estratégias capazes de permitir aos alunos a manifestação dos seus interesses, reflexões, apropriações e elaborações de novos conhecimentos. Fato que nos leva a crer que a aprendizagem durante o desenvolvimento dos projetos de iniciação científica, na perspectiva dos professores, se constitui como um processo que permite a ampliação dos sistemas de significação dos alunos.

Durante o desenvolvimento dos projetos referentes ao Projeto Pixel ficou evidenciado que o papel do professor foi o de acompanhar os alunos, respeitando o tempo e os interesses dos mesmos. Nesse sentido, as etapas da iniciação científica estão em consonância com uma proposta construtivista, na qual, "aprender é reconstruir os conhecimentos a partir dos saberes à disposição e poder dar explicações. Isto será possível graças à presença de alguém que acompanha com o aluno o procedimento de recriação dos conhecimentos." (Dolle, 2008 p.3)

\section{Considerações finais}

Este estudo preliminar indica que a partir dos projetos de aprendizagem na modalidade iniciação científica existe a possibilidade de emergir um modelo de currículo em rede, Web Currículo. Isso porque as teorizações e inovações propostas pelo grupo de professores estão gerando mudanças substanciais nas condutas dos professores e alunos.

Os dados analisados, neste artigo, evidenciam mudanças nas crenças dos professores em relação a sua visão de ciência e sobre os processos de desenvolvimento da aprendizagem dos alunos. As condutas dos professores e alunos observadas durante $o$ desenvolvimento dos projetos de iniciação científica indicam a elaboração de uma proposta pedagógica desenvolvida a partir dos interesses dos alunos, primando pela valorização da sua autonomia e curiosidade.

Observou-se que a utilização dos laptops educacionais, em sala de aula, se deu fundamentalmente como suporte para registro e divulgação dos conhecimentos produzidos pelos alunos e que o grupo de professores já incorporou as listas de discussão e o compartilhamento documentos através de Wikis.

Nas próximas etapas do estudo pretende-se analisar os materiais produzidos pelos alunos com o objetivo de compreender como se dão as elaborações conceituais desenvolvidas durante os projetos de iniciação científica. Acredita-se que a principal contribuição deste trabalho será fornecer subsídios para instituições que se sintam desafiadas a superar um modelo empirista de ensino, não apenas dizendo por que fazêlo, mas fundamentalmente fornecendo indicadores de como fazê-lo.

\section{Notas}

${ }^{1}$ Maiores informações sobre $\quad$ o projeto esta disponível em: http://www.uca.gov.br/institucional/projetoPiloto.jsp

${ }^{2}$ A Comissão de Ensino corresponde a coordenação pedagógica do CAp. Ela é composta por um professor representante de cada departamento, o professor coordenador do Núcleo de Apoio ao Ensino NAE, um representante do conselho de unidade e um representante dos alunos. Com exceção do representante do NAE, que é de escolha da direção da escola, todos os representantes são eleitos por seus pares para fazerem parte da comissão.

${ }^{3}$ Optamos por utilizar a terminologia atual, ou seja, anos no lugar de séries. No entanto, cabe ressaltar que a somente em 2013 teremos turmas de $9^{\circ}$ ano no Ensino Fundamental. No ano de 2012 o projeto Pixel é composto por turmas de sétima e oitavas séries. 
${ }^{4} \mathrm{O}$ Nvivo é um software de análise qualitativa e quantitativa de dados. Ele facilita o armazenamento dos dados e a categorização dos mesmos.

\section{Referências}

ASSIS, M. P., et all. Web curriculum-The Integration of ICT in Education. In: E-Societ 2010, Anais: IADIS International Conference of the Information Society, Porto, 2010 ALMEIDA, M. E. de; SILVA, M. G. M. Currículo, tecnologia e cultura digital: espaços e tempos de web currículo Revista e-curriculum, São Paulo, v.7 n.1 Abril/2011. Disponível em: http://revistas.pucsp.br/index.php/curriculum Acesso: junho 2011

BOGDAN, R. C. e BICKLEN, S. K., Investigação qualitativa em educação. Porto: Porto Editora, LDA, 1994

DOLLE, J. E se a pedagogia pudesse tornar-se científica? In.: SCHÈME Revista eletrônica de psicologia científica. Volume $\mathrm{I} \quad \mathrm{n}^{\mathrm{o}} \quad 1 \quad \mathrm{Jan} / \mathrm{Jun}, \quad 2008$ http://www.marilia.unesp.br/scheme Acesso em:24.01.2012

FAGUNDES L., L. SATO, D. MAÇADA. Aprendizes do Futuro: As Inovações Começaram! Coleção: Informática para a mudança na Educação. MEC/PROINFO, Brasília, 1999.

HOFFMAN, D., FAGUNDES, L.C. da. Cultura Digital na Escola ou Escola na Cultura Digital? In: RENOTE. Revista de Novas Tecnologias na Educação, V. 6 No 1, Julho, 2008

FULLAN, M. O significado da mudança educacional. Porto Alegre: Artmed, 2009.

FULLAN, M. Educação para o aperfeiçoamento contínuo Ano XII - No 46 Educação para o desenvolvimento sustentável -In: Pátio Maio à Julho 2008. Disponível em <http://www.revistapatio.com.br/numeros_anteriores_conteudo.aspx?id=628> Acesso: 16.04 .2012

PIAGET, J. A equilibração das estruturas cognitivas: problema central do desenvolvimento. Rio de Janeiro: Zahar, 1975.

PIAGET, J. O possível e o necesário: evolução dos possíveis na criança.V.1 Porto Alegre: Artes Médicas, 1985

MORAES, R.; GALIAZZI, M. C. Análise textual discursiva: processo reconstrutivo de múltiplas faces. In Ciência \& Educação, v. 12, n. 1, p. 117-128, 2006 